wrist. No other bones were affected and there was no albuminuria. Dr. Greg by the $x$ rays found changes typical of rickets in both wrists, more marked in the ulna than in the radius. All the other bones examined were normal. If you look at the photograph of the wrists on the screen, you will, I think, see confirmation of the history that has been given-namely, a duration of only a few months. There are a sbarp margin and cup-shaped edge at the lower end of the ulna. In the more advanced case last seen the lower edge of the diaphyses has lost its definition. The shaft is, of course, of normal density.

It would be extremely interesting, and important to our patients and their friends, if we could explain how and why this disease arises. I cannot pretend to be able to do this, but I should like to make a few remarks.

Adolescent rickets must, I think, be looked upon as practically the same disease as infantile rickets, modified in some respects by the age of the patient. The question naturally arises as to whether the adolescent form is merely a continuation of infantile rickets or entirely a fresh and -distinct development. It might, of course, be a recrudescence of what the child had suffered in infancy. Against this latter view is the fact that on recovery from infantile rickets the bones are as a rule sclerotic, a condition in which one would imagine a relapse would be unlikely to occur. On the other hand, if it be considered to be a continuation of infantile rickets, the first attack must have been very mild in severity and without any tendency to recovery. For there is no history to be obtained of sufficient severity by which we can say definitely that the patient has suffered from rickets in infancy. I am inclined, therefore, to look upon adolescent rickets in many cases as a distinct development of the same disease arising in circumstances which are chiefly due to the age of the patient. If this be accepted we must assume that rickets may arise at any age from infancy to adolescence. In a great measure one would imagine the same causes would be at work to produce the same changes in the bones. Although we naturally attribute to diet the main responsibility for infantile rickets, we do not deny the influence of the hygienic surroundings of the patient's home. In fact, whatever interferes with metabolism of the body would be likely to prevent the normal development of the bones. One of the most important of these influences upon metabolism must be the higher nerve centres which, unimportant in infancy, are quickly developing towards the age of puberty. We must therefore, I think, acknowledge that new factors arise which are scarcely present in infancy, and which are of as much importance as food, if not more. The period of from 12 to 14 years of age is a time of great intellectual stress from the educational point of view, and anyone who has seen much of children will know what this may mean to many. In some children the competition of school life may produce all sorts of nerve trouble, from insomnia and night terrors to epileptiform convulsions or facial distortion and mimicry. The same intellectual strain and competition will continue throughout the adolescent period of life or even longer. This is more important than diet at this age, for if it be a cause of this trouble it is difficult to eliminate, and accounts perhaps for the long continuance of the adolescent cases. It is noticeable that in two of $\mathrm{my}$ patients diet can have had but little influence, as they were the children of fairly well-to-do parents. In the first case there is evidence of prolonged mental strain during school life and in the second the patient had reached the sixth standard of the board school at from 12 to 13 years of age. The latter fact perhaps only proves that she was not a backward child.

Sexual development is another factor and may have a farreaching effect. It is difficult to judge of this, but in one of my patients (in a case recorded in 1886) premature sexual development was a marked feature. Want of air and exercise must also have a definite influence when once the disease has started, and may therefore be considered as a contributory cause. It probably has also a primary influence among the poor. I would look, therefore, for a variety of causes to produce such results as are seen in the patient whose age is now 23 years and whose wrists showed signs of active rickets two years ago.

There does not appear to be any special treatment applicable to cases of adolescent rickets. The habits and conduet of the patient must be inquired into and action taken in accordance with what is discovered. Diet, education, and fresh air are likely to be the most important points for inquiry. I am inclined to think that correction by osteotomy of a deformity due to this disease should be postponed till all active signs of rickets have disappeared. We occasionally see a recurrence of deformity after correction by operation. It is possible that this is due to the continuance of the same disease which caused the deformity. In the first patient, now aged 23 years, thyroid extract was given for six months last winter. I cannot say for certain that his improvement is due to this drug, but the fact remains that he now feels stronger than he has done for some years and that his lower limbs are better able to sup. port the weight of his body. The bones of the wrists also show, I think, a marked improvement compared with their condition in 1904.

There are a large number of radiographs on the table, besides those which I have shown by the epidiascope. These were all taken by Dr. Greg and presented to the museums of the Royal College of Surgeons of England and St. Thomas's Hospital. I am indebted to Mr. Shattock for the opportunity of showing them here to-night. There are also two specimens on the table. One is from the museum of the Royal College of Surgeons of England. It is a specimen of a rickety femur from a girl, 17 years of age, and was presented to the museum by Mr. E. Muirhead Little who has kindly consented to say a few words on the subject. The other specimen, from the Hospital for Sick Children, Great Ormond-street, is a femur from a child, 12 years of age, who was under the care of Sir Thomas Barlow in 1887. The disease bad been noticed from the age of five years. The patient died from tuberculosis.

\section{STOKES-ADAMS DISEASE AND CARDIAC ARRHYTHMIA.}

BY JOHN HAY, M.D. VICT., M.R.C.P. LOND.,

PHYSICIAN TO THE STANLEY HOSPITAL, LIVERPOOL; PHYSICIAN TO THE HSTIAL TOR COYSUMPION AND DISEANRS ; THE CHES'l, LIVERPOOL; PRESIUENT OF THE MAYCHESTER MICROAND

STUART A. MOORE, B.A. NEW ZEAL., M.D. EdIN., LATE HOUSE PHXSICIAX, STAXLEY HOSPITAL, IIVERPOOL.

IN THE LANCET of Jan. 20th, 1906, p. 139, one of us reported a case of bradycardia and cardiac arrbythmia. The bradycardia was due to heart-block; the block was caused by depression of conductivity. Later this function became practically normal and the block which persisted was found to be caused by depression of excitability. Since the record published as stated the patient has died. His condition became more serious, he suffered from syncopal attacks associated with convulsions, and on May 16 th his illness terminated in a fit. A necropsy was made and the heart was submitted to Professor A. Keith for a report on the auriculoventricular bundle (the $a v$. bundle). ${ }^{1}$ The information obtained from a careful analysis of the many tracings considered in conjunction with the post-mortem findings in the heart is of considerable interest and value in the comprehension of the pathology of this disease. We propose to give a short account of the course of the illness up to the patient's death and to discuss the points of interest which arise.

History of the case.-After the patient's discharge from hospital on Dec. 8th, 1905, he took great care of himself, exercised caution in his diet, ceased to indulge even moderately in alcohol, and kept his bowels open. For a short time he remained well and then began to notice symptoms of failing compensation, dyspnces, and œdema of the legs. Two weeks prior to his readmission on Jan. 5th, 1906, he "caught cold" and was much 1roubled with a cough and copious expectoration. Shortly after this he entered on a period of liability to fits; these were for the most part of a very slight nature; he would feel lost when walking about, pause for a few moments, and then recover himself. At this time headache was increased, slight dizziness appeared, he was thirsty, and he was troubled with indigestion. On Jan. 4th, the night previous to his admission, this period of liability to fits was terminated at his

For a full description of the a.v. bundle see THF LANCET, August 11th, 1906. The Auriculo-Ventricular Bundle of the Human 
home by a severe, fully-developed attack, with unconsciousness and convulsive movements. On admission his temperature was $100^{\circ} \mathrm{F}$. and it was noticed that he was thinner; intelligence and power of attention were good, and some headache, temporal and frontal, was present, more especially at night. He was a little deaf and complained of dizziness. His complexion was rather dusky and there was a fair degree of cyanosis. The sclerotics were faintly icteric. Rhonchi were present over all the chest and râles were heard at the bases; the percussion note over the right base was impaired and the breath sounds were feeble. The legs and abdominal wall were cedematous. Some ascites was present and the liver almost reached to the umbilicus. The frequency of the radial pulse was from 36 to 44 ; it was regular in force and slightly irregular in time. The area of cardiac dulness was greater than previously. The patient was suffering from bronchitis and failing compensation. He was kept in bed, given a light nutritious diet, and put on a stimulant expectorant mixture, to which was added sodium nitrite. In a few days the heart dulness had returned to its former limits and his general condition was ameliorated.

This, his final stay in hospital, lasted up to May 16th, the day of his death; during this time there were periods in which he was liable to syncopal seizures showing all grades of severity. These periods were characterised by the following prodromal symptoms : an increase of headache, dizziness, and troublesome thirst, some loss of acuteness in hearing and vision, and it was noticed that at these times his skin was greyer. These symptoms were present from Jan. 11th to 18th, from Feb. 1st to 10th, from March 4th to 11th, on March 16th and 17th, and finally for about ten days before he died. Seizures occurred on Jan. 12th, 16th, 17th, and 18th, Feb. 8th, March 7th, 8th, 9th, 10th, and 17th, and May 12 th and 16th. On Jan. 16th and Feb. 8th they were extremely numerous and very severe.

In order to avoid repetition we shall limit our description of the fits to those which occurred on Feb. 8th. During the night of the 7th he slept badly and suffered from a severe headache. The next morning at $8 \mathrm{~A} . \mathrm{M}$. he bad a severe and fully developed attack. At 8.30 A.M. he was propped up in bed conscious and distressed. His head was aching intensely and his mouth was quite parched. He was cyanosed and felt very cold. His temperature was $97^{\circ}$. Brandy was administered and hot bottles were applied; these means failed to check the shivering which continued till noon. By 1 A.M. he was of a good colour and comparatively comfortable. He was sitting up in bed when suddenly another attack seized him; no sooner had he recovered and spoken a few words than he was again attacked. He made one or two hurried respirations, his head fell on his breast, and he sank on to his pillow breathing stertorously; his cheeks and alæ nasi flapped in and out; he ceased breath ing, his eyes closed, but his pupils were widely dilated and the eyeballs were turned upwards and to the left. His face was ashen grey, the malar flush had vanished, and he bad all the appearance of a corpse. In a little, however, the colour gradually returned to his face, he sighed deeply and woke up. He raised himself a little, stared about, and then sank back on the pillows exhausted and sweating. During the seizure the radial pulse could not be felt until just before the return of consciousness. For the rest of the day he continued at intervals to have similar attacks. They were all severe, sometimes two or three followed each other in rapid succession, consciousness not being fully regained in the interval. In some of the fits stertorous breathing persisted throughout; in others respiration ceased entirely. Convulsive movements did not always occur; when they did they came on towards the end of the seizure and varied from slight twitching movements and rigidity to a severe general convulsion. At 6 P.M. the temperature was $102^{\circ}$. Throughout the day irregularity of the heart's action was marked. The usual pulse frequency was 30 ; before an attack it was occasionally found to be from 36 to 48 and once even 52 ; while immediately after the attacks the frequency was much higher, usually over 100. This was of short duration, for in a minute or so the rate dropped to 80 or 60 and soon afterwards to 40 . Long pauses of ventricular silence-e.g., one of 15 seconds-were observed between the seizures, without there being any other disturbance. During the attacks longer pauses-e.g., of 75 seconds-were noted. On two occasions Cheyne-Stokes breathing occurred between the attacks; in the apnoeic pause the pulse was regular; in the excited stage a bigeminal action was present. (See Fig.
10.) Daring the night of Feb. 8th the patient was most restless and only semi-conscious-muttering and groaning. Towards the morning he became more conscious and at 6 A.M. began to complain of severe pain in his head. Throughout this night his pulse was from 60 to 70 per minute ; it had dropped to 52 by 11 A.M. on the 9 th. His mind was then apparently clear and he asked for his pipe. On the 10th he looked worn out but was nevertheless much improved. On waking in the morning he asked if he had been ill and on being questioned said that he had no recollection of the events of the past few days. From this serious condition he steadily improved up to March 4 th, his cough disappeared, and the headache became comparatively slight. On this date he entered on another period of liability to fits with the usual prodromal symptoms. The seizures were neither severe nor numerous and afterwards he was in excellent condition; the pulse was 70 to 80 and the conductivity was normal. Heart dulness was only four and a half inches to the left of the middle line-that is, less than it had ever been since his first admission.

This favourable state of affairs persisted up to March 25th, with the exception of the two days March 16th and 17th, when there were slight seizures. From the 25th to the 29th the pulse frequency had a wide range and varied between 32 and 80 per minute, in spite of which his general condition remained fairly good, and from the 30 th to April 10th his condition was again excellent. From the latter date up to the patient's death he was not so well and complained of frontal headache, dyspncea, and dizziness. On May 8th the bronchitis became worse and he was confined to bed. 0 n the morning of the 12th he felt drowsy, "sick at heart," and "like to tummle." Just before noon he had a serions and unexpected attack. There was no warning. He fell back in bed, bluish.grey, and respiration and pulse ceased to be perceptible for three minutes. There was neither rigidity nor convulsions. The pulse returned for ten seconds and then again ceased, this time for one minute, and finally started off at 128 per minute, continued at this frequency for two or three minutes, and then rapidly dropped to 52 per minute. On the 16 th at noon there was another seizure lasting about two minutes and followed by a temporary pulse frequency of 120 per minute In the afternoon of the same day while one of us was taking records, with the patient propped up in bed and quietly talking, he suddenly slipped back unconscious and ashen grey. His respirations became shallow and his body rigid; the pulse had ceased to be recorded but the auricles continued to contract-in fact, it was the sudden cessation of the radial pulse which first drew attention to the onset of the fit. For three minutes there was no pulse at the radial and no heart sounds were audible. Then a few slight pulsations were detected at the wrist which shortly ceased and the cyanosis became more intense. Artificial respiration was performed and he breathed spontaneously for about 30 seconds. This ceased and although artificial respiration was kept up and other means were used to restore cardiac and respiratory activity there were no further signs of life.

Vecropsy. -24 hours after death the body was rigid. There was slight odema of the legs and ankles. The costal cartilages were calcified. The blood throughout the body was dark and fluid. The lungs were emphysematous. There were some old pleural adhesions. There was half a pint of clear fluid in the right pleural cavity. Signs of chronic bronchitis were present. The left lung weighed 15 ounces and the right 18 ounces. The pericardium was normal and contained a few drachms of clear straw-coloured fluid. The heart and vessels weighed 24 ounces. The coronary arteries were rigid and calcified, the right almost occluded, the occlusion being of old standing. The right auricle and ventricle were dilated and hypertrophied. The pulmonary artery and cusps were healthy. The left auricle was a little dilated and somewhat hypertrophied; the endocardium of the septal wall was striated. The mitral valve just admitted three fingers and the chordæ tendinea were somewhat opaque. The aortic cusp of the mitral showed a slight patchy thickening towards its base. The left ventricle was hypertrophied and dilated. The aortic valve was competent to the water test and the cusps were healthy. There were slight dilatation of the first part of the arch of the aorta and a few patches of atheroma, the largest situated just beyond the point at which the pulmonary artery crossed the aorta. The peripheral arteries were a little thicker than normal. The stomach showed numerous petechiæ. The liver weighed three pounds six ounces and was somewhat 
nutmeg in appearance. The kidneys together weighed $12 \frac{1}{2}$ ounces; they contained a few small cysts, their surface was rather irregular, the capsule stripped easily, and the cortex was slightly diminished. The vessels did not stand out on section. The spleen weighed $5_{\frac{1}{4}}^{\frac{1}{4}}$ ounces, was tough, and its capsule was thickened in patches. The pancreas and intestines were normal. The skull was very thick. The dura mater was thick and adherent in places to the arachnoid; there was slight excess of fluid under the arachnoid. There was sclerosis of the internal carotids and also of the vertebral arteries; the basilar artery was fairly normal. At no spot on the circle of Willis was the lumen of the vessels seriously encroached on. The fourth ventricle was apparently normal.

With his usual kindness Professor Keith made a micro. scopical examination of the $a . v$. bundle and from his report I quote the following: "The coronary arteries and the branch of the right coronary artery that runs through the bundle were atheromatous-thickening (irregular) of the intima and also of the sheath. The central fibrous body was an atheromatous mass. At the point of perforation (of the $a v$. bundle) there are patches of a recent inflammatory process. There are patches of cells resolving into fibroblasts : the inflammatory process does not involve the whole bundle ; it is patchy." He also points out that the central fibrous body is stretched and the musculature attached to it and in its near neighbourhood is shrunken and fibrosed. In this distension of the central body the $a . r$. bundle is involved; the pars membranacea septi is stretched, distended, and ras lost its form.

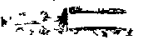

Treatment.-This was largely symptomatic. For the bronchitis the patient received the usual remedies. His diet was light and plain. For exercise he walked about the grounds of the hospital. His hearaches were much relieved by ten grains of phenacetin but it was found necessary to combine three grains of caffeine with the phenacetin, otherwise the dizziness was aggravated. One such powder gave relief for 12 hours. Nitrites were also exhibited for some time without much appreciable benefit. Syrup of iodine and tannic acid cansed him to feel uncomfortable and had to be discontinued. Thyroid was administered over the greater part of his last stay in hospital. The exhibition of the thyroid is marked in the charts (Figs. 1 and 2) and its relationship to the pulse frequency and conductivity can be seen at a glance. From Jan. 20th to 23rd he received five grains a day, then from Jan. 24th to March 7th, and from March 11th to March 26th, and from April 12th to 18 th he received ten grains daily, while from April 18th to May 16th the daily dose was increased to 15 grains. We had hoped that this treatment might possibly improve the conductivity of the a.v. bundle by increasing metabolism. However, conductivity varied irrespectively of the administration of the thyroid. From Jan. 20th to March 7th, during which time thproid was taken continuously, the variations in conductivity were considerable and apparently independent of the thyroid. We refer

Explanation of Figures.

Fig. 1. -The chart in Fig. 1 is a graphic representation of the variations in conductivity and pulse frequency. Conductivity is indicated by the thick line. The degree of conductivity was obtained by analysing simultaneous tracings of the jugular and radial pulses. Note the variations during the first administration of thyroid the thrroid administration is indicated by a straight horizontal line at the foot of the chart. Note that conductivity was normal from March 10th to 17th and again frem March 29th to April 6th. The thin line indicates the pulse frequency as charted by the nursing staff morning and evening. From March 7 th to 10 th and from the 25 a to frequencs to 10th and from the 20th to the 28th the chaency was constantly tarying. The fits occurred as charted. During the fits the pulse ceased. Note that the variations in conductivity were not necessarily associated with the incidence of fits. The systolic blood pressure was occasionally registered. It is recorded in the upper thirc of the chart. When conductivity was normal the reading existed the pressure varied from 200 to $250 \mathrm{~mm}$. of $\mathrm{Hg}$.

Fig. 2.-The chart in Fig. 2 is a graphic representation of the variations in conductivity in relation to the frequency of the auricles and ventricles. The thick line indicates conductivity, the thin line auricular frequency, the dotted line ventricular frequency, wbile the double horizontal line shows when the patient was taking thyroid. Note the variations in auricular frequency during the first administration of thyroid extending from Jan. 20th to Taris 7th. frech 7 . Before the 63 per man thy six who aur was recorded as 66 . in the interval it had been as high as 100 per mirute and as low as 56 .
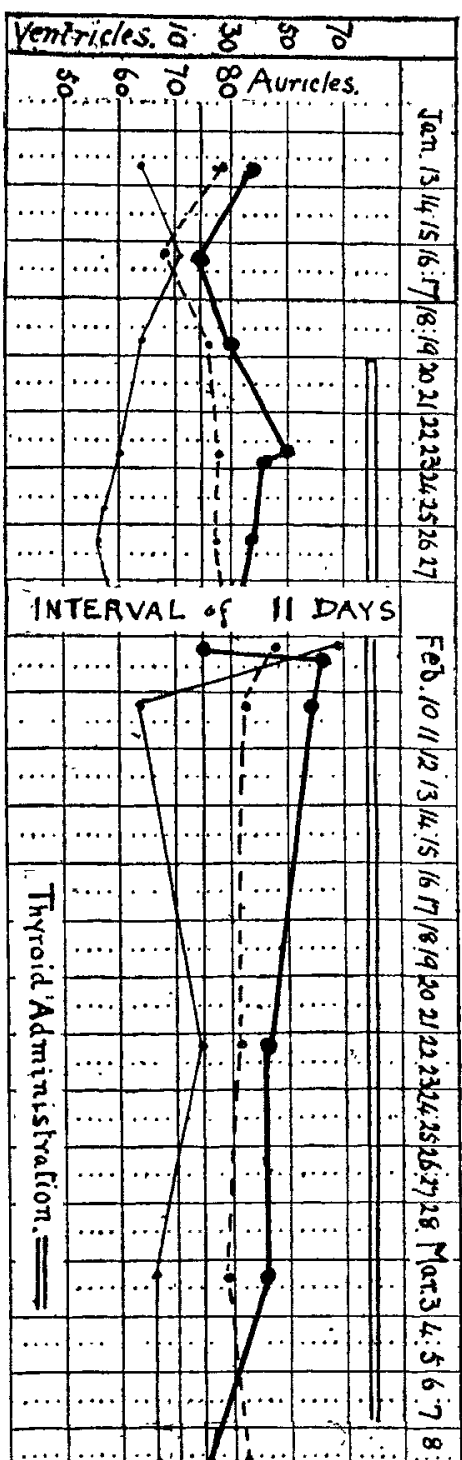

붐

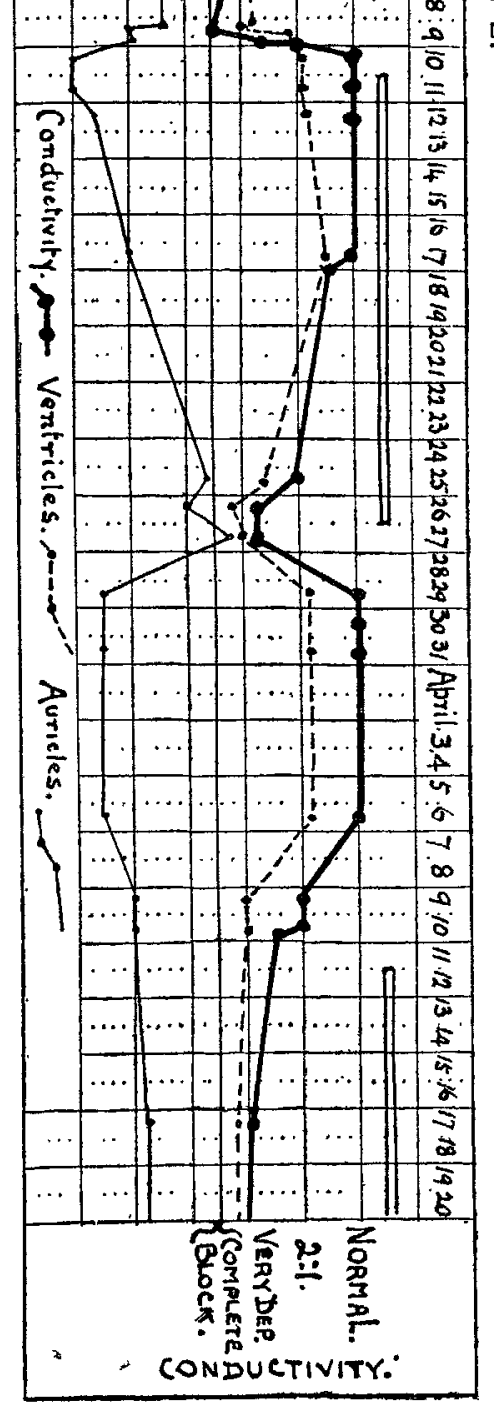

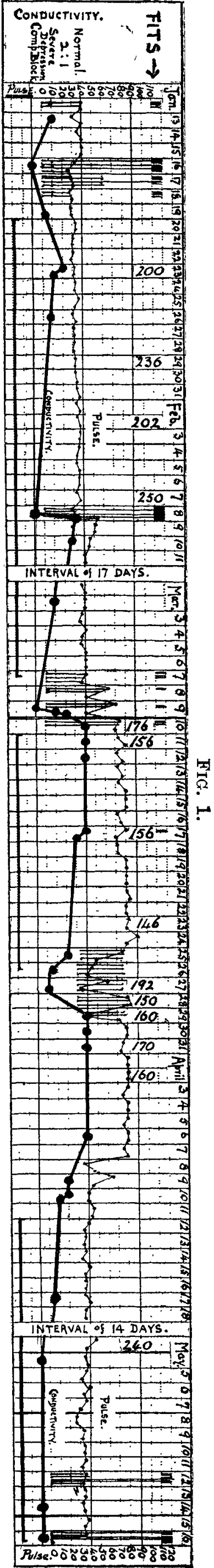


later to the relationship of the variations in auricular frequency and the thyroid administration.

The variations from the normal cardiac rhythm met with in this patient were many and interesting. They can be classified as follows: (1) those associated with, and caused by, variations in conductivity; (2) those caused by the oceurrence of extra systoles, both auricular and ventricular in origin; $(3)$ those caused by depression in the excitability of the cardiac muscle; (4) those caused by impaired contraotility of the ventricle; and (5) a peculiar bigeminal form of pulse occasionally found during complete block.

These variations can best be considered by reference to simultaneous tracings of the radial and venous pulses. In Fig. 3 we have a tracing showing normal conduction along the a.v. bundle. This record was taken on March 12th, 1906, shortly after a series of seizures. In it we see that the inter-systolic time, the ao interval, is just one-fifth of a second. This ac interval is measured from the beginning of the wave $a$ to the beginning of the ware $c$ and is normally one-fifth of a second. It is so in Fig. 3. Similar tracings were obtained from March 10th to 17 th and from March 29th to April 6th. (See Fig. 1.) Fig. 4 shows a slight prolongation in the $a o$ interval. The conducting power of the bundle is becoming impaired and the passage of the stimulus from the auricle to the ventricle is somewhat delayed. In Fig. 4 the auricle is beating less frequently than

FIG. 3.

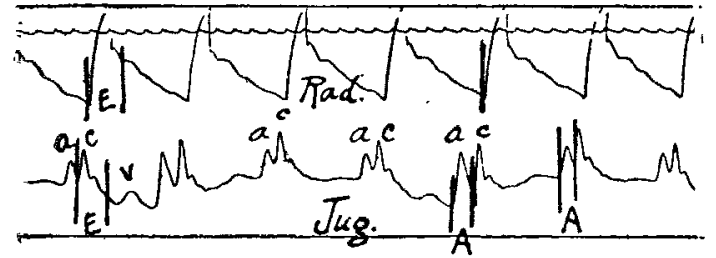

FIG. 4.

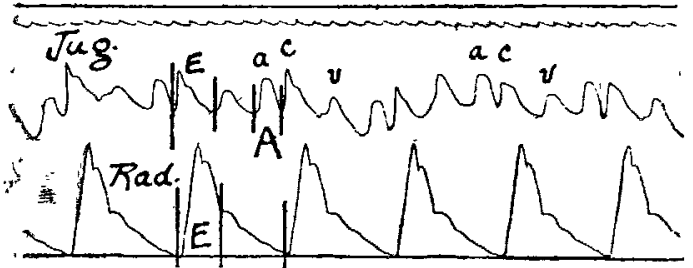

FIG. 5

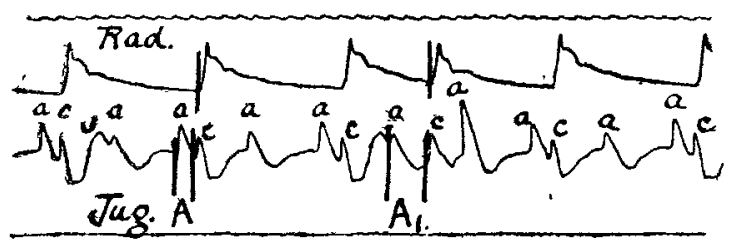

FIG. 6.

\begin{tabular}{|l|l|l|l|l|l|l|l|l|}
\hline$A_{s}$ & & & & & & & & \\
\hline$a_{v}$ & & & & & & \\
\hline
\end{tabular}

ExplandTION OF Figures.

Fig. 3 -Tracing taken on March 12th, 1906. Showing conduetivity normal. The Space $\mathbf{E}$ indicates in all the tracings the period of ventricular systole during which the senailunar valves are open, the sphygmic period. The wave $a$, preceding the period $\mathbb{E}$, can only be due to the systole of the right auricle. The wave $c$ is due to the impact of the carotid pulse. The space A represents the intersystolic time - the a $a$ interval-and indicates the time taken by the stimulas to pass from the auricle to the ventricle. It is here one-fifth of a second which is normal. The time marker records one-fifth of a second. This applies to all tie tracings.

F\&g. 4.-Tracing taken on Sept. 29th, 1905, showing slight depression of conductivity. The $a c$ interval $A$ is more than in Fig. 3 .

Fxy.5.-Tracing taken on March 25th, 1906. It shows that every second auricular systole is blocked. The ac interval A is normal the time allowed by two auricular cycles beine sufficient completely to restore onductivity ycles being sufficient completely to restore conductivity. At one point two successive auricular systoles get through and the result of the too early passage of a stimulus.

Fig 6 . Diagram constructed from the venous pulse in Fig. 5. A $s=$ auricular systoles. $a v=$ the passage of the stimulus along the $a . v$. bundle and indicates the length of the $a c$ interval. $V s=$ ventricular systoles. in Fig. 3. An increased auricular frequency cannot therefore be blamed for the depression of conductivity observed in this tracing. In Fig. 5 we find a $2: 1$ rhythm, every second systole of the auricle failing to initiate a ventricular response. Conductivity is therefore more depressed than in Fig. 4. In this tracing the $a c$ interval is normal. The inference is that the time between any two ventricular systoles is sufficient to enable conductivity to be completely restored. At one point in the tracing the regular 2:1 rhythm is interfered with and two consecutive auricular systoles initiate a ventricular response. As a result of thus diminishing the time allowed for the recovery of the bundle, the second stimulus passes much more slowly along the $a v$. flbres and the length of the $a c$ interval is doubled. Note that the wave $a$ following on this long $a c$ interval is very ample, the cause being that at this point the waves $v$ and $a$ have become superposed. The diagram Fig. 6 still further demonstrates the sequence of events. In this tracing the time occupied by two auricular cycles is sufficient to enable the $a . v$. bundle to recover itself and the $a s$ interval is practically normal. When the conductivity becomes still further depressed the $a c$ interval increases in duration in spite of the fact that the bundle has had the time of two auricular cycles in which to recover. Fig. 2 in THE LANCET of Jan. 20th, 1906, p. 141, is a good example of such a condition present for months in 1905 . In the tracing (Fig. 7) taken on March 27 th we find conductivity much more depressed than in the previous tracings. An analysis of such a tracing is almost impossible without the aid of a diagram; we have therefore drawn up Fig. 8. In this we find a state of affairs revealed which at first sight suggested the existence of complete block, because at $x$ and $y$ the auricles and ventricles apparently contracted together, and also because there appeared to be no regularity in the variations in the $a c$ interval. However, further consideration of the tracing suggests the explanation expressed in the diagram-namely, that we are here dealing with a combination of a $3: 1$ and a $2: 1$ rhythm.

As a rule the ventricle responds to every third auricular systole as in the case with the III., IV., VI., VII., VIII. $X$, and XI. ventricular systoles recorded in the tracing; the II. V., and IX., however, are the response of the ventricle to the second auricular systole and it is interesting to note that when the ventricle responds to every third auricular systole, thus allowing the $a . v$. fibres time to recover, the $a c$ interval steadily diminishes until it becomes normal as at I., VIII., XI.; following on this improvement the second auricular systole gets through and a $2: 1$ rhythm starts, but the depression of conductivity caused by this is so great that the $a \cdot c$ interva is again greatly lengthened and a series of a $3: 1$ rhythm is initiated which lasts until the conductivity permits a 2:1 rhythm, the occurrence of which again so disturbs conduction that a $3: 1$ rhythm is necessary, and so forth. We have numerous tracings showing interesting variations of this nature, but the above will suffice. Th next two tracings were obtained during a condition of com. plete block. Fig. 9 was taken on Jan. 16 th, after the patien had suffered from several seizures. It was noticed that following on these seizures he remained ill and liable to exacerbations of marked bradycardia; these were often accompanied by an increase in the intensity of the headache The tracing exemplifies such an exacerbation. In Fig. 9 the auricular frequency is 64 and the ventricular about eight per minute. Another tracing opens with a very prolonged pause in ventricular action. During this pause of at least ten seconds, ten auricular systoles are recorded, and more must have occurred as the full duration of the ventricular stoppage is not recorded on the tracing. Fig. 10 is perhaps the most interesting of all the records and is certainly the most difficult to explain. It was obtained in the afternoon of Feb. 8th. On analysing this tracing and constructing the diagram, Fig. 11, one sees that the block is complete and that the auricular and ventricular rhythms differ and are independent. In the radial tracing a bigeminy is present. This bigeminy is not continuous, for towards the middle of the record two normal beats occur indicated by $x$. Tracings of a similar nature obtained from patients suffering from complete heart block have been recorded by Goteling Vinnis and Wenckebach. ${ }^{2}$ The two normal beats above referred to may be taken as indicating

2 Vinnis (Goteling): De aanboudende Verdubbeling van den Hartslag. Wenckebach (K. F.): Beitrage zur Kenntnis der Menschlichen Fig. 2c. 
the inherent rhythm of the ventricle at this time and some of the more interesting points. These charts are based each is about six-fifths of a second in duration. It is interesting to note that the second beat in each bigeminy is of the same duration as those marked $x$. For a full discussion of this condition we refer our readers to Wenckebach and Vinnis. Wenckebach, in conclusion, expresses it as his conviction " that doubled and continuous (mehrfache) beart activity must be regarded as an expression of a peculiar condition of the heart; as a peculiar pathological phenomenon, and that it plays a significant rôle in conditions of cardiac arrhythmia."

The tracing (Fig. 10) also indicates some failure in on an analysis of over 200 trucings of the radial and renous pulses. In Fig. 1 we record the variations in conductivity, in relation to the seizures, to pulse-frequency, and to the administration of thyroid. These variations are indicated by a thick line; black dots signify the days on which tracinge were taken from which the conductivity was calculated. The fine lines show the pulse-rate as recorded in the morning and evening by the nurses. The occurrence of fits is indicated in the second space below that in which the day of the month is shown. The horizontal black line at the foot of the chart Fig. 7 .

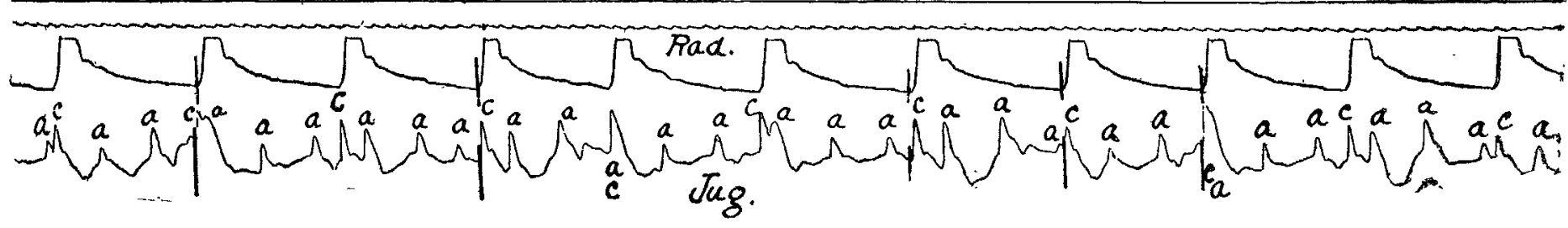

Frg. 8.

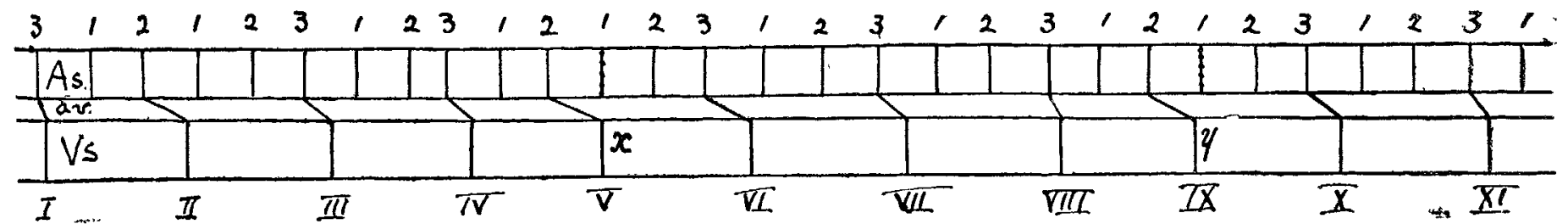

FIG: 9.

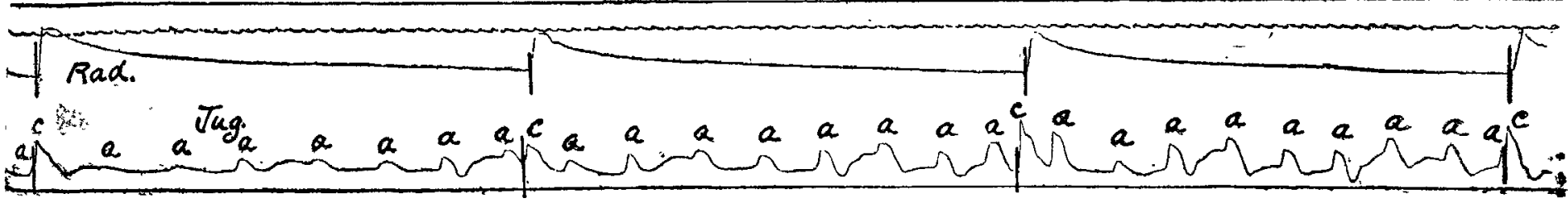

FIG. 10.

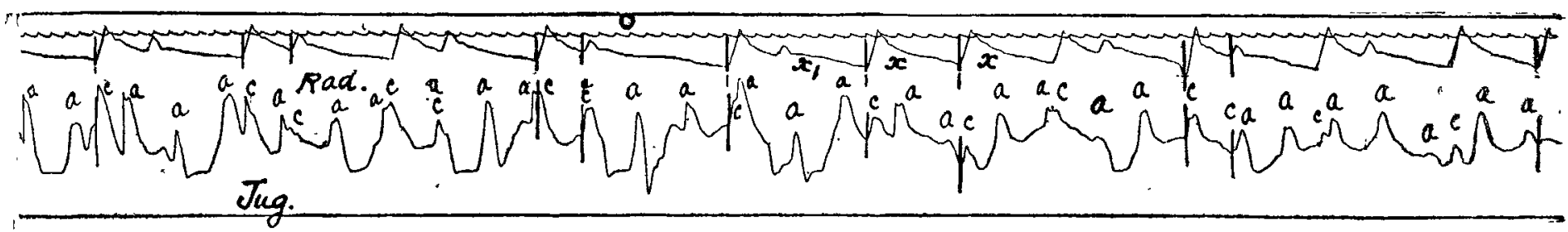

FIG. 11 .

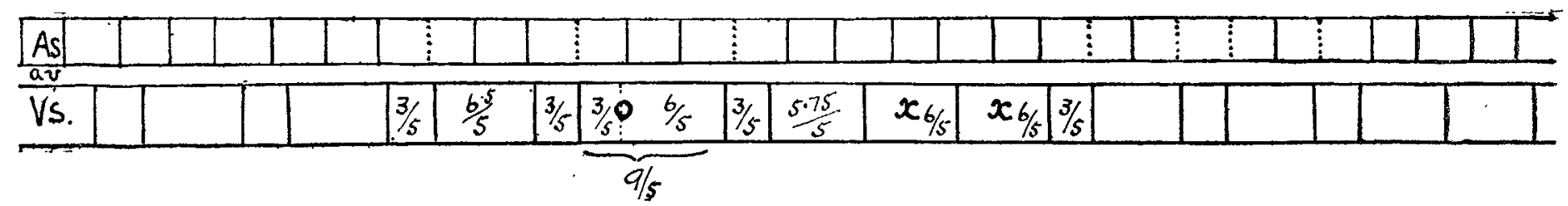

EXPLA NaTION OF Figures.

Fig. \%.-Tracing taken on March 27th. Showing a combination of a $2: 1$ and a $3: 1$ rhythm. The $3: 1$ raythm allows conductivit to recover, while the $2: 1$ rhpthm causes serious depression. At $x$ and $y$ the auricles and ventricles contract together, becanse the $a c$ interval has been so prolonged.

Fig. 8 is a chart constructed from Fig. 7 ; the upper numerals refer to auricular systoles, the lower to ventricular systoles.

Fig. 9. - Tracing taken on Jan. 16th, 1906, betw een the seizures. It shows extreme bradycardia and auricle beating independently.

Fig. 10.-Tracing taken on Feb. 8th, 1906, the day of most severe fits. It shows a condition of complete block. The normal ventricular rbythm is seen at $x x$ and is six-fifths of a second. Note that the second element of the bigeminy as $x_{1}$ is throughout of the same duration as $x$. An exception occurs at 0 , where the duration is nine-fifths of a second. The first element ia the bigeminy averages about three-fifths of a second. At $o$ therefore it is probable that another ventricular systole occurred too weak and feeble to open the aortic valres. Depression of contractility is well seen in this tracing.

Fig. 11.-Diagram constructed from Fig. 10 ; the numbers refer to the duration of the ventricular systoles and represent fiftis of a second.

contractility. This failure is seen in the diminished size of the second element in the bigeminy. Other forms of arrhythmia were met with caused by extra systoles. Extra systoles of both auricular and ventricular types occurred. Extra systoles arising in the ventricular wall were met with after the seizures of March 10th and again following the depression of conductivity noted on March 27th. The variations in pulse frequency caused by depression of excitability in the cardiac musculature have been recorded in THE LANCET of Jan. 20th, 1906. We have drawn up two charts which demonstrate in a graphic manner at once that there were marked variations in conductivity; all grades from the normal to complete block were in evidence at one time or another. On two occasions. Feb. 8th and March 7th, there was a great improvement in conductivity subsequently to aseries of seizures. This improvement lasted for some days and was then followed by a period of depression, while on March 28th the same sequence of events was recorded with this notable exception, there were no fits. This fact is most interesting and demonstrates that the subsequently improvement in conductivity was not dependent on the occurrence of fits. The fits were a consequence rather 
of the depression and instability of the function of conductivity. It is interesting to note how the pulse-frequency increases as conductivity improves and vive versâ.

In Fig. 2 we record the conductivity as before and compare it with the auricular and ventricular frequency. The auricular and ventricular frequency are calculated from the venous and radial pulse tracings. The administration of thyroid is shown by the two horizontal lines in the upper portion of the chart. This chart demonstrates marked variations in the auricular frequency which at first sight might appear to be the result of the administration of thyroid. This, however, is probably not the case, because we find similar and marked fluctuations in the auricular frequency occurring during the prolonged and uninterrupted administration of thyroid from Jan. 20th to March 7th. On Jan. 19 th, the day before the patient began to take thyroid, the auricular frequency was 63 , on Jan. 23 rd it had fallen to 60 on Jan. 26 th to 56 , and on Feb. 8th it was recorded as 100. On Feb. 10th it had again fallen to 63 , rising to 75 on Feb. 22nd. On March 2nd, the last record before the temporary cessation of the thyroid, the auricle was beating at 66. The auricular frequency appears therefore to vary independently of the administration of thyroid. We mention this because the chart from March 7th to April 10th certainly suggests that the variations in auricular frequency were the outcome of the exhibition of thyroid. For this reason it is unfortunate that the exhibition of thyroid was stopped on March 7th when the fits began and all routine treatment was in abeyance. So far as we know this method of charting the conductivity in relation to auricular and ventricular frequency is new, and we believe that observations carried out over long periods and charted in this manner will do much to help to a better understanding of the determining factor in the seizures.

In this patient the a.r. bundle was partially obliterated; it was functionally and organically below normal. As a result of this damage to "the pathway of the stimulus to contraction" a 2:1 rhythm had to our knowledge been present for months and probably, judging from the history, for years. Organic lesions of the $a . r$ bundle are, as a rule, progressive, and this man did not prove an exception. In January, 1906, he entered on what one may term the second stage of Stokes-Adams disease and began to suffer from syncopal and epileptiform seizures. Such seizures usually occurred in groups and were preceded by certain prodromal symptoms which indicated an increased liability to fits Subsequently to these attacks the patient felt much better and on several occasions quite well. At such times conductivity was normal. Variations also occurred in conductivity, irrespective of the occurrence of convulsive seizures.

In this case two factors at least must be considered of importance: (1) The organic changes in the $a v$. bundle which were demonstrated post mortem; and (2) nervous influences which either directly affected the conductivity of the remnant of the bundle or which altered the auricular frequency increasing it and so depressing conductivity by diminishing the resting periods of the bundle. It will probably be urged that the variations in auricular frequency were directly due to the action of the thyroid. There can, of course, be no doubt that the tendency of the thyroid would be to increase this frequency, but a careful consideration of the first half of Fig. 2 leads us to hold the view that there were agents other than thyroid affecting the auricular frequency. These agents were of varying intensity, causing great fluctuations in the degree of conductivity: note that serious depressions were followed by periods in which the conducting power of the damaged bundle was far above its normal. This is most suggestive of a vagus influence, and if it were not that the periods of depression were associated with increased auricular frequency we would feel inclined to ascribe these changes to vagal activity. Gaskell has shown that stimulation of the vagus first lowers conductivity, and in the case of a $2: 1$ rhythm may cause complete block; later, as an after-effect of such stimulation, it greatly increases the conducting power and may even transform a $2: 1$ into a normal rhythm. The stimulation of the vagus required to bring about this change in conductivity need only be slight, and such slight stimulation does not necessarily affect auricular frequency. This is beautifully shown in a tracing published by one of us in the Manohester Medioal Chronicle for September, 1906. It was obtained from a patient of Dr. James Mackenzie suffering

3 Gaskell : The Contraction of Cardiac Muscle, Text-book of Physiology, vol. ji. Edited by Schäfer. from early aortic and mitral disease. ${ }^{*}$ The slight stimulation of the vagus produced by swallowing was sufficient to bring about temporary block, and two ventricular systoles dropped out as a consequence.

An analysis of the tracings in this patient revealed a slight but persistent depression of conductivity. The vagus was consequently acting on an already functionally abnormal bundle and accordingly was potent. The increase in the depression of conductivity was not associated with any slowing of auricular frequency, and thus the tracing is a beautiful example of the selective action of the vagus, one function responding to the depressing effect because already damaged, the other escaping. Another example of the fact that a bundle damaged functionally or organically differs in its response from the normal bundle is found in the effect of digitalis on the heart. ${ }^{5}$ Digitalis when pushed has no effect on conductivity unless the function is before the administration of the drug already below the normal. If there be a persistent depression in conductivity the digitalis still further increases this depression and eventually causes the dropping out of ventricular systoles and a tracing is obtained similar to that referred to above.

Summary in conclusion. - In this communication we have recorded a case of Stokes-Adams disease in its second stagethat is, in the stage of syncopal, apoplectiform, or epilepti. form seizures. These seizures were of all grades of severity and tended to occur in groups with periods of comparative comfort intervening. The advent of seizures was usually indicated by definite prodromal symptoms. The necropsy revealed partial obliteration of the $a . v$. bundle; this would cause a persistent depression of conductivity. An analysis of numerous tracings revealed marked variations in conductivity, all grades from normal conduction to complete heart block being in evidence at one or another time. This suggests influences in addition to the organic lesion. Such influences were probably nervous in character and affected conductivity eitber directly through the vagus or indirectly by altering the auricular frequency,

\section{NOTE ON}

DETERMINATIONS OF THE AMOUNT OF PHYSIOLOGICALLY ACTIVE HYDROCHLORIC ACID IN THE STOMACHS OF NORMAL MICE AND OF MICE

\section{SUFFERING FROM CANCER EXPERIMENTALLY} PRODUCED.

By S. MONCKTON COPEMAN, M.D. CANTAB., F.R.S., LECTURER ON PUBLIC HEALTH, WESTMINSTER HOSPITAL MEDICAL SCHOOL;

$$
\text { AND }
$$

H. WILSON HAKE, PH.D., F.I C.,

LECTURER ON CHEMISTRY, WESTMINSTER HOSPITAL MEDICAL SCHOOL.

THE main object of our experiments has been to ascertain whether an increase or decrease of physiologically active $\mathrm{HCl}$ could be demonstrated in the stomachs of "cancer mice" with either ulcerated or non-ulcerated tumours, as compared with normal mice.

The experiments, which extended over the period December, 1905 , to June, 1906, have involved the examination of over 500 stomachs in seven series, with an average number of 70 in each series, including all three classesA (normal), B (non-ulcerated tumours), and C (ulcerated tumours). Dr. E. F. Bashford, director of the Imperial Cancer Research Fund, to whom we are indebted for the necessary material, arranged that the mice should be killed one hour after a full meal of bread and milk, and that the stomachs should be sent to us for examination as speedily as possible after death.

The method adopted for determining the physiologically active $\mathrm{HCl}$ was that described by Dr. W. H. Willcox, of St. Mary's Hospital, in THE LANOET, ${ }^{1}$ with such small modifications as seemed desirable for our special purpose. The modus operandi is as follows. The stomachs belonging

4 See also Brit. Med. Jour., Oct. 27th, 1906, p. 1110. 5 Mackenzie (J.) : The Action of Digitalis on the Human Heart, Brit. Med. Jour., March and April, 1905.

1 The LANoeT, June 10th, 1905, p. 1566. 